\title{
Impacto da notícia da síndrome de D own para os pais: histórias de vida
}

\author{
Impact of delivering the news about Down syndrome on parents: \\ life stories
}

Aldine M aria Fernandes Vohlk Cunha ${ }^{1}$

Silvana M aria Blascovi-Assis ${ }^{1}$

Geraldo Antonio Fiamenghi Jr. ${ }^{1}$

Abstract This paper aimed to know and discuss a group of parents of Down syndrome children reactions and feelings and the impact of the news and diagnostic. Four couples whose children received the diagnostic of Down syndrome participated in thisresearch. Data were collected through a semi-structured interview and the results were qualitatively analyzed, using categories. Results indicated that all four couples relate the feeling of loss of the idealized son. It can be observed from this study the need for professional capacitating because the impact of the moment the family re ceive the news can interfere in the family's dynamic, as well as in the child's development. Key words Down syndrome, Family, News
Resumo Este trabalho teve como objetivo conhecer e discutir as reações e sentimentos vivenciados por um grupo de pais de crianças com síndrome de D own referentes ao impacto da notícia e do diagnóstico. Participaram da pesquisa quatro casais, que têm filhos com o diagnóstico de síndromede D own. O sdadosforam coletadosatravés de uma entrevista semi-estruturada e os resultados foram analisados de forma qualitativa. Os resultados indicaram que todos os casais relataram o sentimento de perda do filho idealizado. Pode-se perceber, a partir deste estudo, a necessidade da capacitação profissional, uma vez que o impacto gerado por este momento pode interferir na dinâmica familiar e, consequentemente, no desenvolvimento da criança.

Palavras-chave Síndrome de Down, Família, Notícia
${ }^{1}$ Pós-Graduação em

Distúrbios do

Desenvolvimento,

Universidade Presbiteriana

M ackenzie. Ruada

Consolação 896, Prédio 16

sala 03. 01302-907 São

Paulo SP.

aldinefv@hotmail.com 
Introdução

A chegada de uma criança com deficiência em uma família pode gerar situações complexas e resultantes da falta de preparo einformação adequada para lidar com os sentimentos que possivelmente surgirão nesse momento. Atitudes de superproteção, piedade ou rejeição, presentes no núcleo familiar, podem interferir no desenvolvimento dos filhos, incluindo os aspectos sociaise emocionais ${ }^{1}$.

A síndrome de Down, causa mais comum da deficiência mental, éfacilmente diagnosticada no período imediato ao nascimento, devido às suas características peculiares, sendo a notícia transmitida aos pais por ocasião do nascimento ${ }^{2,3}$. $\mathrm{H}$ oje, vem sendo cada vez mais frequente o conhecimento desse diagnóstico ainda no período gestacional, em decorrência dos exames cada vez mais precisos para levantar a suspeita da síndrome, que é confirmada pelo exame de cariótipo. Um estudo ${ }^{4}$ realizado com 44 gestantes submetidas aos métodos de diagnóstico pré-natal citogenético detectou um caso de constatação da síndromede D own, cuja continuidadefoi interrompida por decisão familiar. Os autores comentam que, embora o grupo estudado fosse predominantemente católico, a grande maioria demonstrava a intenção de aborto no caso de resultados positivos para a presença da síndrome. Estes re sultados, embora provenientes de um grupo específico, que procurava já no período gestacional a notícia de possíveis alterações, podem ilustrar parte da dificuldade em se lidar com o tema e com o significado social de se ter na família uma pessoa com deficiência.

Estudos envolvendo a representação social da síndrome de Down vêm mostrando que as mães desenvolvem imagens e pensamentos sobre seus filhos considerando os significados construídos coletivamenteeatribuídos pela sociedade ocidental a estas crianças ${ }^{5}$. Sigaud e Reis ${ }^{6}$ chamam a atenção para a predominância de sentimentos negativos expressos pela representação social de mães de crianças com esta síndrome sobre seus filhos, levando-as a experimentar sentimentos ambivalentes e comportamentos de superproteção. Um estudo observou que o mecanismo de defesa mais usado pelas mães foi a negação, como forma de diminuir ou encobrir a problemática do filho, para ganhar tempo para a elaboração do choqueinicial ${ }^{7}$.

Considerando que os pais nunca planejam o nascimento deum filho diferente, pode-se supor que grande parte da reação inicial à notícia da síndrome será determinada pelo tipo de informação recebida, a maneira como ela é apresentada e a atitude da pessoa que faz a comunicação ${ }^{8}$. Frequentemente, a notícia não é transmitida de maneira adequada, fazendo ampliar o sofrimento e, consequentemente, trazendo mais dificuldades para a aceitação desse filho ${ }^{9}$. Algumas vezes, a maneira profissional e objetiva dos médicos pode causar a indignação dos pais; por isso, é importante que o bebê seja apresentado à família detal maneira que seus atributos easpectos normais sejam ressaltados. 0 médico deve considerar o período de desorganização que os pais experimentam durante os estágios de choque e negação, sabendo que informações sobre as condições e a evolução da criança terão que ser repetidas várias vezes ${ }^{10}$.

Vários autores ${ }^{7,11}$ salientam que os profissionais precisam ter uma linguagem adequada, para oferecer aos pais informações claras, objetivas e atualizadas no momento da notícia. Não se deve falar neste momento sobre prognóstico e é importante dar tempo para os pais absorverem as informações e fazerem suas perguntas.

0 diagnóstico da síndrome de Down transforma-se num marco na vida da família, desencadeando um processo de reorganização que envolve cinco estágios ${ }^{12}$. No primeiro estágio, observase 0 choque; neste momento, muitos pais confidenciaram que esteperíodo inicial era uma época de comportamento irracional, com muito choro, sentimento dedesamparo e, ocasional mente, uma ânsia por fugir. No segundo estágio, é observada a negação e muitos pais tentam escapar da informação da anomalia de seus filhos. No terceiro estágio, é observada reação emocional intensa, como tristeza, raiva e ansiedade. No quarto estágio, ocorre a adaptação dos pais, em que estes começam a seaproximar afetivamentedo bebê. Já o quinto estágio corresponde a uma reorganização da família. Além dos sentimentos clássicos e da dificuldadeem aceitar o diagnóstico, existeainda a constante busca da cura da síndrome?.

O impacto das alterações provocadas pela síndrome deve ser de conhecimento dos profissionais, para que a implementação de programas específicos possa ter maior alcance, considerando que a família tem um importante papel na inserção da criança em seu contexto sociocultural ${ }^{13}$. Pareceexistir uma dificuldade enormena relação entre o médico e os pais da criança, devido à deficiência na formação médica, do ensino da relação médico-paciente, habilidade imprescindível à prática médica ${ }^{14}$, evidenciando a importância de que os futuros profissionais médi- 
cos/psicólogos/fisioterapeutas sejam mais bem preparados para 0 atendimento ao deficiente e aos seus familiares ${ }^{15}$. Além disso, é imprescindível que haja uma interdisciplinaridade entre os profissionais, pois estes precisam saber de sua área de formação e dar contribuições para outras áreas para o pleno tratamento da criança e sua família ${ }^{16}$. Os profissionais (fisioterapeutas, fonoaudiólogos, terapeutas ocupacionais, assistentes sociais, psicólogos e pedagogos) que trabalham em programas de estimulação global precisam estar atentos ao fato de que os pais, provavelmente, só poderão discutir e entender as orientações profissionais depois que estes tiverem passado a fase que pode ser chamada de "luto" pelo filho idealizado ${ }^{17}$. E, finalmente, em respeito às famílias, é fundamental que a notícia seja dada aos pais conjuntamente.

Portanto, este estudo teve como objetivo conhecer as reações, os sentimentos eas experiências de um grupo de pais de crianças com síndromedeD own, referentes ao momento da notíciae do diagnóstico, identificando a maneira como as famílias receberam a notícia, as reações maternas e paternas diante do impacto dessa comunicação, o conhecimento familiar sobre a síndrome deD own eas sugestões dos pais direcionadas aos profissionais para lidar com esse momento.

\section{Método}

Este estudo foi de caráter qualitativo e optou-se por utilizar entrevistas semi-estruturadas, uma vez que, para atender aos objetivos propostos, foi necessário apreender um momento específico da vida destes pais, o que só pode ocorrer através de relatos do que cada um deles vivenciou.

Participaram da pesquisa quatro casais, que têm filhos com o diagnóstico de síndrome de Down. Ascrianças eram do sexo masculino, com idade entre um a quatro anos e frequentavam, na época da coleta de dados, um programa de estimulação global. Os pais foram mencionados como P1 eM 1; P2 e M 2; P3 e M 3; P4 e M 4.

Os critérios de inclusão foram a faixa etária da criança, a transmissão do diagnóstico da síndrome de Down aos pais durante o período pré natal ou até os dois primeiros meses de vida e a constituição deuma família nuclear, isto é, aquela composta por pai, mãe e filhos, vivendo sob um mesmo teto, unidos por laços sanguíneos e de matrimônio ${ }^{18}$.

0 critério de exclusão foi a criança apresentar, além da síndrome de D own, outros diagnós- ticos associados, como paralisia cerebral, autismo, cardiopatias graves e outras síndromes.

A pesquisa foi realizada numa instituição particular, sem fins lucrativos, de utilidade pública municipal, estadual efederal, localizada em Campinas, interior do Estado de São Paulo. Os participantes assinaram o termo de consentimento livree esclarecido após a leitura da carta de informação, em que se definia a inexistência de risco para os participantes, a possibilidade de retirarse da pesquisa a qualquer momento e o sigilo quanto à sua identidade. 0 projeto de pesquisa foi aprovado pelo Comitê de Ética em Pesquisa da UPM (processo no476/03/04).

A entrevista semi-estruturada apresentou questões sobre o momento da notícia, as reações e sentimentos dos pais, informações que receberam sobre a síndrome de Down, período de adaptação e também o que estes aconsel hariam aos profissionais responsáveis pela notícia e pelo diagnóstico.

Cada casal foi entrevistado uma vez, com a duração de uma hora, aproximadamente. As entrevistas foram gravadas com o consentimento do casal entrevistado e posteriormente transcritas, respeitando-se com exatidão a maneira como cada um se expressou. Três casais foram entrevistados juntos (pai emãe) eum casal separadamente, por dificuldades de compatibilização de horário.

A pós a transcrição, as entrevistas foram lidas e analisadas de acordo com os temas discutidos na literatura pesquisada, tendo em vista os objetivos deste trabalho.

\section{Resultados ediscussão}

Todos os casais receberam a notícia da suspeita da síndrome de Down no prazo máximo de dois dias após o nascimento, sendo que um dos casais entrevistados recebeu esta notícia ainda no segundo mês de gestação. Os profissionais que comunicaram a notícia para os casais entrevistados foram o obstetra, o pediatra e o médico da UTIN (unidade deterapiaintensiva neonatal). A notícia recebida em tempo imediato após o nascimento da criança é relatada por alguns autores ${ }^{2,3}$, devido às características inconfundíveis da síndrome de Down, que é reconhecida logo no momento do nascimento, sendo que o diagnóstico definitivo é feito através do exame de cariótipo.

Três casai s receberam a notícia separadamente, enquanto apenas um casal a recebeu enquanto estavam juntos. $\mathrm{Na}$ maioria dos casos, os 
médicos deram a notícia primei ramente ao pai, mas em um dos casos o pai (P4) recebeu a noticia através da esposa que havia sido informada da suspeita da síndrome pela médica no ultrassom, ainda durante a gestação.

$\mathrm{Na}$ pesquisa de Pasqualin ${ }^{14}$, os médicos entrevistados relataram que preferem comunicar primeiro ao pai sobreo diagnóstico deuma anomalia congênita e isto também foi observado nesta pesquisa. Porém, entre os autores que estudam o tema, é consenso de que a notícia seja dada na presença dos dois, pai e mãe ${ }^{11,19-21}$.

Quanto à forma como foi dada a noticia, todos os médicos foram direto ao assunto, sendo queem um caso o médico apenas levantou a suspeita sobre um aspecto sindrômico. O s entrevistados relataram em todos os casos, a falta de informações mais esclarecedoras sobre o problema.

Olha, mãe, seu filho está ótimo, a glicemia está ótima apesar de ele ser baixo peso, o barulhinho é um barulhinho quea traquéia éainda muito imatura, então faz mesmo, depois com o tempo passa. A única coisa éque ele é sindrômico, então você só cuida disso daqui uns cinco anos, você procura um geneticista, uma estimulação; isso era umas onze horas da noite, e foi embora (M 3).

$M$ as o médico ainda falou, não sei, são mais de cinco mil síndromes, dezenas, milhares de síndromes, como é que eu vou saber, isso é para vocês investigarem depois com calma, o bebê está super bem (P3).

Então foi através da translucência nucal , eu tava sozinha, efoi como eu te falei, ela avisou pra mim quetinha $97 \%$ de chance de ser Down (M 4).

Especificamente em M 3, observa-se que a informação compreendida e relatada pela mãe mostra uma falta de orientação sobre como proceder com a criança nos primeiros anos de vida, já que o médico sugeriu, segundo a mãe, que o auxílio terapêutico fosse buscado por volta dos cinco anos de idade. No mesmo caso, P3 relata que o médico disse não saber qual síndrome poderia estar relacionada ao seu filho, ressaltando que conhecia mais de cinco mil síndromes. Asinformações mal transmitidas podem estar relacionadas ao desconhecimento sobre a síndrome de Down ou ainda podem refletir a dificuldade mé dica em comunicar o diagnóstico provável ${ }^{14,15}$.

A forma como M 4 recebeu a hipótese diagnóstica revela a falta de noção sobre os sentimentos que podem ser vivenciados neste momento, por parte do profissional que transmitiu a informação, já quea comunicação foi feita para a mãe sozinha, durante um exame de rotina na gestação. É muito importante comunicar a notícia ao casal, transmitindo todas as informações necessárias sobre o problema, de forma objetiva eclara, propiciando abertura para discutir o problema e sanar as possíveis dúvidas dos pais ${ }^{11}$.

Com relação às reações, as mães relataram um sentimento de perda do filho idealizado, sendo que M 4, por estar recebendo a notícia antes do nascimento, teve um sentimento predominantemente de desorientação.

A minha reação era só chorar, a sensação que te dá equevocêesta levando um tiro. Eu tinha a sensação quemejogavam terra em cima demim, eu estava viva, mas de repente eu saía por causa do meu filho. M as a sensação é a pior possível, é de desproteção, castigo, parece que você está sendo castigado por Deus.Você chora mesmo a morte do filho, e aí eu ficava assim, ah, meu Deus, porqueeu estou chorando, se o meu filho está vivo lá. 0 meu filho que eu esperava, eu chore ele morto mesmo (M 1).

A sensação era que meu filho, o meu filho, aquele que eu esperei, não era o meu filho, que estava ali, entendeu. É muito medo do desconhecido. Então é assim eu chorei muito, muito, muito, muito, mas não fiquei depressiva. Todo dia, a hora que eu acordava, eu lembrava, nossa, meu filho tem síndrome de D own eagora? (M 3).

Então na hora, lá dentro, eu não senti nada, não caiu a ficha, foi cair lá embaixo. E aí o que aconteceu, eu sai pela rua, fiquei desatinada, atravessei a rua, os carros passando um atrás do outro, eu só ouvia buzina, fui pra um lugar que eu morava. Chegando lá perto que eu vi que não era lá mais que eu já estava morando. Cheguei em casa, mas cheguei assim, eu tava nervosa, tinha chorado muito. Eu queria só dormir, não queria ficar acordada (M 4).

Segundo Vash ${ }^{19}$, todos os pais vivenciam o choque e o medo com relação à notícia, como podemos verificar nos relatos anteriores, bem como a dor e a ansiedade de se pensar como serão as expectativas para o futuro da criança. Em geral, todos os casais pesquisados experimentaram a perda do filho idealizado. Esse sentimento traduziu-se, neste estudo, por manifestações como vontade de dormir, pelo susto em acordar e lembrar a presença da síndrome na vida familiar e pelo choro relatado por todas as mães. Os sentimentos parecem não diferir em sua natureza frente ao comunicado da notícia em situação de gestação ou após o nascimento. As angústias, o luto e a preocupação fazem-se presentes em ambas as circunstâncias.

Entretanto, os programas de apoio aos familiares devem ser elaborados para atender as 
necessidades de cada momento. A mulher gestante necessita subsídios para o enfrentamento desse período até o nascimento da criança, enquanto que a família que recebe a notícia após a chegada do bebê deve ser orientada e apoiada para cuidar do filho e buscar o tratamento mais indicado.

A perda do filho idealizado aconteceu, nesse estudo, para pais e mães, aliada à preocupação com o quadro clínico da criança e alguns sentiram indefinição, até receberem o resultado do cariótipo.

No momento que ele me falou que ele era síndrome de Down, a gente sente um sentimento de perca [sic], porque você está esperando uma criança saudável quevenha sem problema, um filho perfeito, mas não tem como expressar o sentimento de perca [sic] mesmo. Vocêpensa assim, porquetinha que acontecer comigo e tem tanta gente que vem normal (P2).

A minha reação é eu não chorei, eu não tive crise, eu nunca rejeitei a criança. Eu senti tristeza. Parece que não foi o filho que eu esperei. Nasceu alguém, meu filho, mas não foi este que eu esperei. Puxa meu filho vai ser deficiente. $\mathrm{Na}$ verdade, a gente viveu muito assim, uma sensação de indefinição, porqueo médico não nos disseassim, oh este é o quadro de síndrome de Down, o médico disse: tem um aspecto sindrômico, pode ser, mas pode não ser (P3).

O depoimento dos pais mostra uma atitude mais realista frente à situação vivida, mesmo que permeada pela tristeza e pelo sentimento de perda. Embora a maioria dos trabalhos relate o discurso da mãe, éimportanteque o pai possa ser ouvido e tenha sua fala e suas expectativas analisadas ${ }^{22}$.

Todos os casais entrevistados tiveram pouca ou nenhuma informação sobre a síndrome de Down no momento da notícia, sendo que nenhum médico que transmitiu a notícia atendeu às expectativas dos pais, como podemos observar nos depoimentos a seguir:

Ela não falou nada, falou só queera a síndrome deD own, não falou nada quetinha que fazer terapia, ela falou que era mais molinho (P1).

Ele não deu muita informação, ele só perguntou se eu conhecia a síndrome de D own e quando eu falei que eu não conhecia, que eu tinha uma vaga idéia do que seria, aí ele falou: que era mongolismo e que ele não era a pessoa mais preparada para me explicar no momento, só me disse que era um problema genético (P2).

Como podemos verificar neste último depoimento, o médico assume não ser a pessoa me Ihor preparada para explicar a síndrome. Parece que a maioria dos profissionais não se encontram preparados, técnica ou emocionalmente, para lidar com esse acontecimento, e podem experimentar al guns sentimentos como ansiedade, desconforto e impotência ao ter que comunicar a notícia para os pais ${ }^{11,14,17}$.

Observou-se, nesse estudo, que os pais passam, de fato, pelos cinco estágios descritos, quando recebem a notícia da anomalia do seu filho ${ }^{12}$. Pode-severificar queos sentimentos experimentados foram choque, negação, raiva, tristeza e culpa, atéque haja uma adaptação ereestruturação familiar, confirmando os achados na literatura?.

Alguns depoimentos revelam a vivências desses sentimentos, reafirmando a necessidade do apoio emocional nesse momento.

Vocêchora o filho que morreu, realmente morreu. A té depois entender que no lugar está aquela criança com síndrome de Down, até lá você chora muito, até você entender, o que aconteceu, e o que vai acontecer, o queestá acontecendo em sua volta. Você nega o tempo todo, vocêfala ele tem os olhos puxadinhos, mas eu também tenho, você até puxa seus olhos. Ele não tem síndrome de Down, você nega todo momento, você procura assim, querer mostrar pros médicos que eles estão errados (M 1).

Em relação aos sentimentos, olha até hoje eu acho ainda vai me dá depressão, que é normal. Será que eu não vou ficar deprimida, ou tal, claro que tem dias que você vê que eu quero, que agora ele esta na fase que ele quer falar e não sai, né. Eu fico triste de ver, eu fico pensando mais quando ele entrar numa escolinha, né? (M 3).

Quando foi perguntado aos casais como eles explicariam a síndrome de seu filho, estes responderam tentando repassar todo o conhecimento que possuíam:

Um acidente genético, quenão foi culpa nossa. Q ue ele tem atraso mental, que tem que fazer fisioterapia e fono, que tem dificuldade de apreender, tal. M as, no mais, que ele pode trabal har, podeestudar, que ele pode fazer tudo que outro faz também (P1).

Síndrome de Down é uma deficiência mental que afeta bastantea partemotora, bastantea parte cognitiva, mas que são seres humanos com enorme potencial que os programas de estimulação, as clínicas especializadas, conseguem orientar e obter um excelente resultado no aspecto motor. Que estas crianças conseguem ir à escola, aprender a ler, avançar na escola, conseguem trabalhar, conseguem inclusão, bastante próximo daquilo que a gente chama de indivíduo normal (P3).

As sugestões levantadas pelos entrevistados para contribuir para que esse momento se torne 
menos traumático revelam desejos e lacunas vividas por ocasião da notícia e do diagnóstico. Entre elas, destacam-se a forma e as informações que gostariam de receber. Segundo as mães e pais participantes, os médicos deveriam dar a notícia um ou dois dias após o nascimento, falar sobre todos os aspectos inerentes à síndrome de Down, incluindo os problemas que estas crianças podem ter, como problemas cardíacos e problemas respiratórios, e a importância da estimulação precoce. Se possível, a mãe nunca deveria estar sozinha no momento da notícia, devendo estar sempre acompanhada pelo marido ou parente. 0 casal $\mathrm{M} 3$ e P3 sugeriu a presença de um grupo de apoio, proporcionando troca entre casais que já passaram pela experiência de ter um filho com síndrome de Down. Foi sugerida por M 4 a presença de um psicólogo junto com o médico neste momento.

Observou-se que nenhum dos participantes deste estudo teve apoio de um psicólogo, o que poderia ser um caminho para que o casal pudesse ser acolhido e conseguisse vivenciar e expressar seus sentimentos com suporte profissional. É interessante ressaltar que nenhum dos textos consultados na literatura sugere a presença deste profissional no momento da notícia, como membro da equipe hospitalar. A presença desse profissional em momento tão delicado vem sendo pouco explorada, inclusivenos casos de diagnósticos pré natais. Ainda em relação à participação do psicólogo no momento da notícia, observase quase uma unanimidade quando se fala sobre os sentimentos presentes, principalmente em estudos realizados com mães no período pós-notícia; porém, a participação em grupos de apoio imediato vem sendo pouco relatada em pesquisas. N ota-se ainda que os estudos envolvendo 0 interesse nessa temática da notícia da síndrome de D own concentram-se na década de noventa.

\section{Conclusões}

Os profissionais responsáveis pela comunicação da notícia e do diagnóstico da síndrome de D own devem estar constantemente preocupados com o preparo para este momento tão delicado para a vida de um casal, para que seja menos traumático para a família eque esta tenha melhores chances para superar esta fase e contribuir de modo mais tranquilo para o pleno desenvolvimento da criança.
Os sentimentos comuns vivenciados pelos pais foram desorientação, choque, perda de uma situação idealizada e ansiedade pel o futuro, principalmente pela desinformação quanto ao quadro clínico da criança. Assim, após o recebimento da notícia e do diagnóstico, é necessário que os pais tenham oportunidades para esclarecimento de suas dúvidas e recebam explicações referentes à condição do seu filho, aliadas ao apoio psicológico, para superar os sentimentos negativos que estão presentes eque podem dificultar as relações posteriores dos pais com a criança. Este suporte supõe contato com uma equipe interdisciplinar, incluindo psicólogos, fisioterapeutas, fonoaudiólogos, terapeutas ocupacionais, assistentes sociais, médicos, entre outros, que devem estar também preparados para lidar com as angústias e receios que cercam a nova realidade familiar. Para tanto, há que se pensar em medidas para intervir na formação desses profissionais.

É importante que os pais possam buscar informações nas instituições especializadas, organizando-se em grupos, para encontrar os meIhores caminhos e informações atualizadas sobrea síndrome de Down, além do apoio e orientações necessárias para o pleno desenvolvimento do seu filho. A instituição proporciona também o encontro entre mães e pais que se apóiam mutuamente, auxiliando na superação dos conflitos quesurgem inicialmentee ao longo do desenvolvimento da criança. Para tanto, é necessário que as famílias sejam orientadas e encaminhadas pelos profissionais que realizam os primeiros contatos, buscando-se assim um trabalho interdisciplinar que melhor atenda as necessidades dos familiares efaciliteo desenvolvimento da criança e o trabalho de toda a equipe.

\section{Colaboradores}

AM FV Cunha, SM Blascovi-Assise G Fiamenghi Jr. participaram de todas as fases da elaboração do artigo. 


\section{Referências}

1. Araújo LAD. A proteção constitucional das pessoas portadoras de deficiência. Brasília: Coordenadoria $\mathrm{Na}$ cional para Integração da Pessoa Portadora de Deficiência; 1994.

2. Casarin S. O ciclo vital da família do portador da síndrome de Down: dificuldades específicas. Temas Desenv 1997; 6(33):18-27

3. Schwartzman JS. Síndrome de Down. São Paulo: M emmon/M ackenzie; 1999.

4. Sartorelli EM P, Paulin-Simon C, Petean EBL, Mazzucatto LF, Bailão LA, Pina-N eto J. Avaliação de famílias submetidas ao diagnóstico pré-natal citogenético. Reprod Clim 1999; 14(1):36-41.

5. Paixão AG. Representações sociais e a síndrome de Down: entre o sofrimento e a sua superação. Arq Bras Ped 1997; 4(5):141-146.

6. Sigaud $\mathrm{CHS}$, Reis AOA A representação social da mãe acerca da criança com síndrome de Down. Rev Esc Enfermagem USP 1999; 33(2):148-156.

7. Brunhara F, Petean EBL. M ães e filhos especiais: reações, sentimentos e explicações à deficiência da criança. Paidéia 1999; 9(16):31-40.

8. Buscaglia LF. Os deficientes e seus pais. Rio de Janeiro: Record; 1993.

9. Brasil. M inistério da Saúde. Informações sobre a síndrome de Down: destinada aos pais. Brasília: Ministério da Saúde/Programa Nacional de Atenção à Pessoa Portadora de Deficiência; 1994.

10. Klaus $M H$, Kennell JH. Pais/bebê: a formação do apego. Porto Alegre: Artes M édicas; 1992.

11. Petean EBL, Pina-N eto JM . Investigações em aconselhamento genético: impacto da primeira notícia - a reação dos pais à deficiência. M edicina (Ribeirão Preto) 1998; 31:288-295.

12. Drotar D, Baskiewicz A, Irvin N, Kennele J, Klaus $M$. The adaptation of parents to the birth of an infant with a congenital malformation: a hypothetical model. Pediat 1975; 56(5):710-717.

13. Silva NL, Dessen MA. Síndrome de Down: etiologia, caracterização e impacto na família Interação 2002; 6(2):167-176.
14. Pasqualin L. O médico, a criança com deficiência e sua família: o encontro das deficiências [dissertação]. Ribeirão Preto (SP): Faculdade de M edicina de Ribeirão Preto, Universidade de São Paulo; 1998.

15. Rocha CR. Deficiência: as reações emocionais do profissional da saúde no momento da notícia [dissertação]. São Paulo (SP): Pós-Graduação em Distúrbios do Desenvolvimento, Universidade Presbiteriana M ackenzie; 1999.

16. Carpenter B. Sustaining the family: meeting the needs of families of children with disabilities. Brit J Spec Ed 2000; 3(27):135-144.

17. Souza LG. Cuidando do filho com deficiência mental: desvelamentos de vivências de pais no seu ser-com-ofilho [dissertação]. Ribeirão Preto (SP): Escola de Enfermagem de Ribeirão Preto, Universidade de São Paulo; 2003.

18. Muncie J, Wetherell M, Langan MD, Cochrane A, editors. Understanding the family. London: Sage; 1999.

19. Vash CL. Enfrentando a deficiência: a manifestação, a psicologia, a reabilitação. São Paulo: Pioneira; 1988.

20. Lefèvre H. M ongolismo: estudo psicológico e terapêutico multiprofissional da síndrome de Down. São PauIo: Sarvier; 1981

21. Leigh J, Marshall S. A terapia dos deficientes e dos pais: um resumo da literatura. In: Buscaglia LF. Os deficientes e seus pais. Rio de Janeiro: Record; 1997. p. 105-114.

22. Lewis C, Dessen MA. O pai no contexto familiar. Psicol Teor Pesq 1999; 1(15):9-16.

Artigo apresentado em 14/11/2007

Aprovado em 28/07/2008

Versão final apresentada em 14/09/2008 